\title{
Persepsi Pengunjung Dalam Pengembangan Wisata Pantai Hamadi di Kota Jayapura
}

\author{
Errick Worabay dan Putu Gede Ariastita \\ Perencanaan Wilayah dan Kota, Fakultas Arsitektur, Desain dan Perencanaan \\ Institut Teknologi Sepuluh Nopember (ITS) \\ e-mail: errickun@gmail.com, ariastita@urplan.its.ac.id
}

\begin{abstract}
Abstrak-Tujuan dalam penelitian ini adalah untuk memberikan arahan pengembangan wisata Pantai Hamadi di Kota Jayapura. Penelitian ini menggunakan pendekatan rasionalisme dengan jenis eksploratif dan deskriptif. Analisis tahap pertama dilakukan untuk menentukan faktor - faktor yang mempengaruhi pengembangan wisata berdasarkan persepsi pengunjung dengan menggunakan skala likert dan analysis service quality (servqual), kemudian analisis tahap kedua menganalisis arahan pengembangan wisata Pantai Hamadi berdasarkan dengan faktor - faktor yang mempengaruhi dengan menggunakan teknik analisis deskriptif. Hasil Penelitian didapat 5 faktor yang mempengaruhi pengembangan Wisata Pantai Hamadi di Kota Jayapura antara lain: Lingkungan Alamiah (Kebersihan dan kelestarian), Sarana Wisata (Tempat Jualan dan Sarana Penunjang), Desain Perancangan, Transportasi, dan Pelayanan yang akan menjadi arahan pengembangan Pantai Hamadi.
\end{abstract}

Kata Kunci-Pariwisata, Persepsi Pengunjung, Pantai Hamadi.

\section{PENDAHULUAN}

$\mathrm{P}$ ERGI berwisata merupakan merupakan salah satu kebutuhan sekunder yang harus dipenuhi manusia selain kebutuhan utamanya. Kebutuhan untuk berwisata merupakan kebutuhan yang dipenuhi untuk memberikan kenyamanan (faktor amenities). Faktor amenities merupakan faktor permintaan yang mendorong perkembangan kota seperti peningkatan akan kebutuhan rekreasi, fasilitas publik, tidak terdapatnya pencemaran dan lain - lain. Kebutuhan ini sangat berguna untuk mengurangi kepenatan selama menjalankan aktivitas sehari-hari. [1]

Kawasan wisata Pantai Hamadi yang berada di sebelah selatan jantung Kota Jayapura sangat memprihatinkan. Minimnya perhatian Pemerintah menyebabkan aset wisata Pantai Hamadi terkesan jauh dari kenyamanan. Hamburan sampah dan gundukan limbah serabut kelapa menumpuk di bibir pantai. Padahal, Pantai Hamadi merupakan salah satu objek wisata andalan masyarakat Kota Jayapura. Selain lokasinya mudah dijangkau karena dekat pusat kota [2]

Dari Hasil Wawancara pada tanggal 16 juli 2016 Pantai Hamadi sebenarnya memiliki keindahan alam menarik. Pantai memiliki bukit dan pepohonan yang rindang, serta rumah-rumah honai dengan atap ilalang seperti halnya di permandian wisata alam di daerah lain pada umumnya . Situasi Kawasan Wisata Pantai Hamadi yang belum ideal untuk menjual produk wisata, dimana penciptaan harapan yang tinggi dan memuaskan dengan kenyataan kinerja pelayanan masih rendah di Pantai Hamadi yang belum sesuai harapan pengunjung.[3] Oleh karena itu perlu dilakukan studi mengenai tingkat pelayanan pada kawasan Wisata Pantai Hamadi Kota Jayapura berdasarkan persepsi pengunjung sebagai upaya- upaya penanganan yang tepat dalam meningkatkan daya tarik Wisata Pantai Hamadi Kota Jayapura. Adapun pertanyaan penelitian yang diajukan dalam penelitian ini adalah "Bagaimana Arahan Pengembangan Kawasan Wisata Pantai Hamadi Berdasarkan Persepsi Pengunjung?".

\section{METODE PENELITIAN}

\section{A. Jenis dan Pendekatan Penelitian}

Pendekatan yang digunakan dalam penelitian ini adalah pendekatan rasionalistik. Jenis penelitian dalam penelitian ini adalah deskriptif dan eksploratif.

\section{B. Variabel Penelitian}

Variabel penelitian yang digunakan untuk menentukan untuk menentukan faktor - faktor pengembangan kawasan wisata pantai Hamadi di kota Jayapura antara lain ada 21 yaitu; keindahan, kebersihan, kelestarian, atraksi, keramahan, tradisi, harga, petugas, penjual makanan, penjual soevenir, tempat jualan, sanitasi, sarana penunjang, sarana rekreasi, aksesibilitas, image, keteraturan, kemananan, keselamata, keserasian dan pedestrian ways. Variabel ini memiliki kemungkinan untuk tereduksi atau muncul variabel baru berdasarkan hasil analisis variabel faktor terkait pengembangan kawasan Wisata.

Tabel 1

Penentuan Variabel Terkait Faktor Pengembangan Wisata

\begin{tabular}{ccl}
\hline \hline Aspek & Faktor & \multicolumn{1}{c}{ Variabel } \\
\hline \multirow{2}{*}{ Aspek Lingkungan Alami } & Lingkungan & Keindahan \\
& Alamiah & Kebersihan \\
& Atraksi Wisata & Atraksi \\
& dan Budaya & Keramahan \\
& & Harga \\
Aspek Lingkungan Buatan & & Petugas \\
& & Penjual \\
& Pelayanan & Makanan \\
& & Penjual \\
& & Souvenir \\
Sarana & & Tempat Jualan \\
& & Sanitasi \\
& & Sarana \\
& & penunjang \\
\hline \hline
\end{tabular}




\begin{tabular}{ccl}
\hline \hline Aspek & Faktor & \multicolumn{1}{c}{ Variabel } \\
\hline \multirow{3}{*}{ Transpotasi } & Sarana rekreasi \\
& & Aksesibilitas \\
& Kesan \\
& Keteraturan \\
& Perancangan & Keamanan \\
& & Keselamatan \\
& Keserasian \\
& Pedestrian ways \\
\hline \hline
\end{tabular}

\section{Metode Pengumpulan Data}

Metode pengumpulan data yang digunakan dalam penelitian ini adalah teknik survei primer yang terdiri dari wawancara dan kuisioner.

Secara praktis, sampel yang diambil menggunakan Purposive Sampling. Pemilihan sampel ini dilakukan dengan sengaja dengan pertimbangan responden dianggap mampu untuk mengerti dan mampu menjawab kuisioner, untuk kuisioner ditunjukkan bagi wisatawan yang mengunjungi pantai Hamadi. Populasi Wisatawan pada kawasan wisata Pantai Hamadi adalah 368600 pengunjung pertahun dan sampelnya adalah rata - rata jumlah kunjungan perhari pada yaitu 102 perhari.

\section{Metode Analisis}

Metode analisis yang digunakan dalam menentukan arahan pengembangan Kawasan wisata pantai Hamadi terdiri dari 2 (dua) tahapan analisis yaitu tahap pertama menggunakan metode Analysis Likert dan Analysis Servqual, digunakan untuk menentukan Faktor - faktor pengembangan Kawasan Wisata pantai Hamadi berdasarkan persepsi pengunjung. Tahap kedua menggunakan metode Analisis Deskriptif, digunakan untuk Menganalis arahan pengembangan kawasan wisata Pantai Hamadi kota Jayapura berdasarkan persepsi pengunjung.

Tabel 2.

Metode Analisis

\begin{tabular}{|c|c|c|c|}
\hline No & Sasaran Penelitian & Teknik & Output \\
\hline 1 & $\begin{array}{l}\text { Menentukan } \\
\text { faktor - faktor } \\
\text { yang berpengaruh } \\
\text { terhadap } \\
\text { pengembangan } \\
\text { kawasan wisata } \\
\text { Pantai Hamadi } \\
\text { berdasarkan } \\
\text { persepsi } \\
\text { pengunjung }\end{array}$ & $\begin{array}{l}\text { Skala Likert } \\
\text { dan Service } \\
\text { Quality }\end{array}$ & $\begin{array}{l}\text { Faktor - } \\
\text { faktorpengembanga } \\
\mathrm{n} \quad \text { kegiatan } \\
\text { berdasarkan persepsi } \\
\text { pengunjung wisata } \\
\text { Pantai Hamadi }\end{array}$ \\
\hline 2 & $\begin{array}{l}\text { Menganalisis } \\
\text { arahan } \\
\text { pengembangan }\end{array}$ & $\begin{array}{l}\text { Analisis } \\
\text { Deskriptif }\end{array}$ & $\begin{array}{l}\text { Arahan Strategi } \\
\text { pengembangan } \\
\text { wisata pantai }\end{array}$ \\
\hline & $\begin{array}{l}\text { wisata Pantai } \\
\text { Hamadi } \\
\text { berdasarkan } \\
\text { persepsi } \\
\text { Pengunjung }\end{array}$ & & $\begin{array}{l}\text { Hamadi } \quad \text { Kota } \\
\text { Jayapura }\end{array}$ \\
\hline
\end{tabular}

\section{HASIL DAN DISKUSI}

A. Menentukan Faktor - Faktor yang mempengaruhi Pengembangan Kawasan Wisata Pantai Hamadi

Berdasarkan hasil analisis yang dilakukan didapatkan nilai tingkat kepuasan (Tabel 3) dan nilai tingkat kepentingan (Tabel 4) untuk menentukan faktor-faktor yang berpengaruh (prioritas) terhadap Pengembangan (Tabel 6)adalah :

a. Lingkungan Alamiah

Faktor lingkungan alamiah dimana kondisi kebersihan lingkungan dan keindahan yang masih memperihatin kan

b. Sarana Wisata

Faktor Sarana Wisata dimana kondisi kenyamanan dan kerapihan tempat berjualan yang kurang dan makanan tradisional yang masih kurang.

c. Desain Perancangan

Faktor desain perancangan keselamatan diri pengunjung baik jiwa dan raga belum terjamin penuh

d. Transportasi

Faktor Transportasi ketersediaan angkutan umum dan aksesibilitas yang memadahi.

e. Pelayanan

Faktor Pelayanan nilai ketepatan waktu pelayanan, kesopanan dan keramahan dalam memberikan pelayanan yang di nilai masih kurang

Tabel 3.

Tingkat Kepuasan Pengunjung

\begin{tabular}{llcc}
\hline \hline No & \multicolumn{1}{c}{ Variabel } & Jumlah & $\begin{array}{c}\text { Mean } \\
\text { Kepuasan }\end{array}$ \\
\hline 1 & Keindahan & 306 & 3 \\
2 & Kebersihan & 294 & 2,88 \\
3 & Kelestarian & 406 & 3,98 \\
4 & Tempat Jualan & 410 & 4,01 \\
5 & Sanitasi & 258 & 2,52 \\
6 & Sarana Penunjang & 306 & 3 \\
7 & Sarana Rekreasi & 324 & 3,17 \\
8 & Atraksi & 318 & 3,11 \\
9 & Hospitality & 318 & 3,11 \\
10 & Kesan & 324 & 3,17 \\
11 & Keteraturan & 264 & 2,58 \\
12 & Keamanan & 346 & 3,39 \\
13 & Keselamatan & 408 & 4 \\
14 & Keserasian & 270 & 2,64 \\
15 & Pedestrian Ways & 318 & 3,11 \\
16 & Transportasi & 218 & 2,13 \\
17 & Harga & 274 & 2,68 \\
18 & Petugas & 330 & 3,23 \\
19 & Penjual Makanan & 396 & 3,88 \\
20 & Penjual Souvenir & 224 & 2,19 \\
\hline \hline
\end{tabular}

Berikut ini merupakan hasil perhitungan likert kepentingan pengunjung.

Tabel 4.

Tingkat Kepentingan Pengunjung

\begin{tabular}{llll}
\hline \hline No & \multicolumn{1}{c}{ Variabel } & Jumlah & $\begin{array}{c}\text { Mean } \\
\text { Kepentingan }\end{array}$ \\
\hline 1 & Keindahan & 306 & 5 \\
2 & Kebersihan & 294 & 5 \\
3 & Kelestarian & 406 & 3,78 \\
4 & Tempat Jualan & 410 & 5 \\
5 & Sanitasi & 258 & 2,5 \\
6 & Sarana Penunjang & 306 & 5 \\
7 & Sarana Rekreasi & 324 & 3,01 \\
8 & Atraksi & 318 & 2,43 \\
9 & Hospitality & 318 & 5 \\
10 & Kesan & 324 & 3,09 \\
11 & Keteraturan & 264 & 2,49 \\
12 & Keamanan & 346 & 3,11 \\
13 & Keselamatan & 408 & 5 \\
14 & Keserasian & 270 & 2,64 \\
15 & Pedestrian Ways & 318 & 3,09 \\
16 & Transportasi & 218 & 5 \\
\hline \hline
\end{tabular}




\begin{tabular}{llll}
\hline \hline No & \multicolumn{1}{c}{ Variabel } & Jumlah & \multicolumn{1}{c}{$\begin{array}{c}\text { Mean } \\
\text { Kepentingan }\end{array}$} \\
\hline 17 & Harga & 274 & 2,17 \\
18 & Petugas & 330 & 2,98 \\
19 & Penjual Makanan & 396 & 5 \\
20 & Penjual Souvenir & 224 & 2,19 \\
\hline \hline
\end{tabular}

Berikut ini adalah hasil perhitungan analisis servqual:

Tabel 5

Selisih Mean (Nilai Servqual)

\begin{tabular}{|c|c|c|c|c|c|}
\hline $\mathrm{NO}$ & Variabel & $\begin{array}{c}\text { Mean } \\
\text { kepuas } \\
\text { an }\end{array}$ & $\begin{array}{c}\text { Mea } \\
\text { n } \\
\text { kepe } \\
\text { nting } \\
\text { an }\end{array}$ & $\begin{array}{c}\text { Mean } \\
\text { selisih/ } \\
\text { nilai } \\
\text { servqu } \\
\text { al }\end{array}$ & Keterangan \\
\hline 1 & Keindahan & 3 & 5 & -2 & Prioritas \\
\hline 2 & Kebersihan & 2,88 & 5 & $-2,12$ & Prioritas \\
\hline 3 & Kelestarian & 3,98 & 3,78 & 0.2 & \\
\hline 4 & Tempat Jualan & 4,01 & 5 & $-0,99$ & Prioritas \\
\hline 5 & Sanitasi & 2,52 & 2,5 & 0,02 & \\
\hline 6 & $\begin{array}{l}\text { Sarana } \\
\text { Penunjang }\end{array}$ & 3 & 5 & -2 & Prioritas \\
\hline 7 & Sarana Rekreasi & 3,17 & 3,01 & 0,7 & \\
\hline 8 & Atraksi & 3,11 & 2,43 & 0,68 & \\
\hline 9 & Hospitality & 3,11 & 5 & $-1,89$ & Prioritas \\
\hline 10 & Kesan & 3,17 & 3,09 & 0,08 & \\
\hline 11 & Keteraturan & 2,58 & 2,49 & 0,09 & \\
\hline 12 & Keamanan & 3,39 & 3,11 & 0,28 & \\
\hline 13 & Keselamatan & 4 & 5 & -1 & Prioritas \\
\hline 14 & Keserasian & 2,64 & 2,64 & 0 & \\
\hline 15 & Pedestrian Ways & 3,11 & 3,09 & 0,02 & \\
\hline 16 & Transportasi & 2,13 & 5 & $-2,87$ & Prioritas \\
\hline 17 & Harga & 2,68 & 2,17 & 0,51 & \\
\hline 18 & Petugas & 3,23 & 2,98 & 0,25 & \\
\hline 19 & $\begin{array}{l}\text { Penjual } \\
\text { Makanan }\end{array}$ & 3,88 & 5 & $-1,12$ & Prioritas \\
\hline 20 & $\begin{array}{l}\text { Penjual } \\
\text { Souvenir }\end{array}$ & 2,19 & 2,19 & 0 & \\
\hline
\end{tabular}

Dari data hasil perhitungan tersebut, maka dapat diketahui nilai servqual yang akan menjadi prioritas dalam pengembangan kawasan wisata Pantai Hamadi Kota Jayapura yaitu sebagai berikut:

1. Tingkat Kebersihan dengan nilai $-2,12$ Tingkat kebersihan di zona wisata ini menandakan sangat kurang. Melihat luasnya kawasan, sehingga pengawasan dalam hal kebersihan tidak bisa maksimal. Oleh karena itu nilai yang dihasilkan dari responden negatif.

2. Tingkat Keindahan dengan nilai -2 Tingkat keindahan disini bukanlah seperti taman atau semacamnya, namun menurut responden keindahan yang dimaksud merupakan jalan yang sudah banyak berlubang, kerikil-kerikil besar bekas perbaikan tambal sulam jalan.

3. Tempat Jualan dengan nilai $-0,99$ Tempat jualan bagi produk masyarakat tradisional sekitarnya sebenarnya sudah disediakan, namun karena sewa tempat yang mahal menjadikan mereka memili berjualan disekitar kawasan wisata yang tentunya selain mengganggu keteraturan, juga merusak keindahan dari tempat wisata tersebut.
4. Sarana Penunjang dengan Nilai -2 Sarana penunjang berupa tempat duduk atau para-para yang kurang terawatt serta mainan anak-anak yang sudah mulai rusak. Hal ini menyebabkan kegusaran wisatawan perihal perawatan fasilitas pendukung obyek wisata tersebut.

5. Keselamatan dengan nilai -1 Keselamatan dianggap responden menjadi salah satu variabel prioritas yang perlu diperhatikan, mengingat letak kawasan wisata pantai Hamadi yang masih kental dengan alam, selain itu juga jalanan yang sudah berlubang dan beberapa titik sepi yang menyebabkan responden khawatir akan keselamatan mereka.

6. Sarana Transportasi dengan nilai $-2,87$ Masih belum adanya sarana transportasi khusus untuk menuju dan pergi dari kawasan wisata pantai Hamadi. Hanya ada ojek-ojek yang sesekali mangkal di pos, sebab kebanyakan mereka datang membawa kendaraan pribadi, namun bagi mereka yang membawa keluarga besar dan tidak memiliki kendaraan pribadi sangat sulit untuk mengakses kawasan wisata.

7. Penjual Makanan dengan nilai $-1,12$ Penjual makanan yang terkesan kurang rapih dan suka memaksa dalam membeli produk yang mereka tawarkan, kiranya menjadi salah satu prioritas variabel untuk dipertimbangkan kedepannya.

8. Hospitality / Keramahtamaan dengan nilai $-1,89$ Keramahan masyarakat disana yang masih minim dan sering terjadi kesalahpahaman atau ada warga yang tersinggung.

Dari ke 8 variabel prioritas tersebut, berdasarkan kepentingan pengembangan kawasan skala makro, direklasifikasikan kembali menurut faktor-faktor sebelumnya, sehingga didapatkan faktor dengan variabel prioritas didalamnya. Faktor-faktor tersebut berupa:

Tabel 4

Faktor - Faktor Pengembangan Wisata Pantai Hamadi Kota Jayapura

\begin{tabular}{cc}
\hline \hline Faktor & Variabel \\
\hline Lingkungan Alamiah & Keindahan \\
Kebersihan & Tempat Jualan \\
Sarana Wisata & Sarana Penunjang \\
Desain Perancangan & Keselamatan \\
Transportasi & Sarana \\
Pelayanan & Penjual makanan \\
\hline \hline
\end{tabular}




\section{Hospitality}

\section{B. Arahan Pengembangan Kawasan Wisata Berdasarkan} Persepsi Pengjunjung

Dari hasil didapat faktor - faktor yang berpengaruh terhadap pengembangan wisata Pantai Hamadi berdasarkan variabel prioritas. Analisis deskriptif dilakukan berdasarkan keadaan eksisting terhadap faktor setelah itu ditinjau dan di tentukan arahan pengembangan wisata Pantai Hamadi secara makro. Berikut hasil analisa deskriptif:

\begin{tabular}{|c|c|c|}
\hline Faktor & Eksisitng & Arahan \\
\hline $\begin{array}{l}\text { Lingkunga } \\
\mathrm{n} \text { Alamiah }\end{array}$ & $\begin{array}{l}\text { - Daerah Rawan abrasi } \\
\text {-Masih ada pemukiman } \\
\text { yang buang sampah ke } \\
\text { laut } \\
\text {-Air laut di jadikan } \\
\text { PDAM } \\
\text { - Beberapa titik } \\
\text { berserakan sampah }\end{array}$ & $\begin{array}{l}\text { 1. Pusat Kegiatan sebaiknya } \\
\text { difokuskan ke tengah (Rawan } \\
\text { Abrasi) } \\
\text { 2. Dilakukan Pembibitan Guna } \\
\text { Melestarikan } \\
\text { keanekaragaman vegetasi dan } \\
\text { tindakan pencegahan abrasi } \\
\text { dan pasang surut } \\
\text { 3. Sosialisasi kepada } \\
\text { pemukiman sekitar Pantai } \\
\text { Hamadi } \\
\text { 4. Diperlukan distribu air } \\
\text { bersih kedalam kamar mandi } \\
\text { atau WC umum }\end{array}$ \\
\hline $\begin{array}{l}\text { Sarana } \\
\text { Wisata }\end{array}$ & $\begin{array}{l}\text { - Masih banyak kios - kios } \\
\text { kosong, sedang banyak } \\
\text { pedang jualan } \\
\text { disepanjang jalan } \\
\text { - Kebanyakan panggung } \\
\text { semi permanen } \\
\text { digunakan untuk music, } \\
\text { bukan hiburan yang } \\
\text { mengangkat budaya } \\
\text { - Jumlah para- para atau } \\
\text { honai yang dirasa } \\
\text { kurang, apalagi kalau } \\
\text { akhir pekan }\end{array}$ & $\begin{array}{l}\text { 1. Mengusulkan atraksi budaya } \\
\text { seperti upacara adat port } \\
\text { numbay, tarian yospan } \\
\text { kedalam salah satu agenda } \\
\text { rutin Pantai Hamadi } \\
\text { 2. Sosialisasi kios-kios } \\
\text { pedagang agar pemilik } \\
\text { menurunkan harga sewa } \\
\text { 3. Pemanfaatan ruang - ruang } \\
\text { kosong sebagai tempat } \\
\text { istirahat wisatawan }\end{array}$ \\
\hline $\begin{array}{l}\text { Desain } \\
\text { Perancanga } \\
\mathrm{n}\end{array}$ & $\begin{array}{l}\text {-Terdapatnya beberapa } \\
\text { titik pada kawasan } \\
\text { disekitar pantai yang } \\
\text { luput dari perhatian } \\
\text { petugas } \\
\text {-Daerah rawan konflik } \\
\text {-Sering terjadi } \\
\text { salahpaham antara } \\
\text { wisatawan dan } \\
\text { masyarakat asli } \\
\text { daerah. } \\
\text {-Masih sering terjadinya } \\
\text { pencurian bahkan } \\
\text { pembunuhan }\end{array}$ & $\begin{array}{l}\text { 1. Mengikutsertakan masyarkat } \\
\text { dalam pengembangan wisata } \\
\text { Pantai Hamadi Kota Jayapura } \\
\text { 2. Membangun kerja sama } \\
\text { dengan Aparat TNI/POLRI } \\
\text { dalam peningkatan mutu } \\
\text { kualitas kemanan dan } \\
\text { keselamatan } \\
\text { 3. Pemasangan CCTV }\end{array}$ \\
\hline $\begin{array}{l}\text { Transporta } \\
\text { si }\end{array}$ & $\begin{array}{l}\text {-Lahan parkir cukup } \\
\text { luas, namun masih } \\
\text { ada yang parkir liar } \\
\text {-Beberapa titik jalan } \\
\text { menuju Pantai } \\
\text { Hamadi rusak dan } \\
\text { berlubang } \\
\text {-Banyak rambu Lalin } \\
\text { yang rusak }\end{array}$ & $\begin{array}{l}\text { 1. Sosialisasi kepada } \\
\text { masyarakat mengenai } \\
\text { berkendara yang baik serta } \\
\text { parkir yang teratur. } \\
\text { 2. Perbaikan akses menuju } \\
\text { Pantai Hamadi (Rambu - } \\
\text { rambu dan sebagainya) }\end{array}$ \\
\hline
\end{tabular}

\begin{tabular}{ccc}
\hline \hline Faktor & Eksisitng & Arahan \\
\hline Pelayanan & - Banyaknya makanan & 1.Perlu dipertahankan budaya \\
& yang disajikan tapi & tradisional dibidang kuliner \\
& sedikit atau masih & seperti papeda dan ikan asar \\
jarang makanan & 2.Pemberian sanksi yang tegas \\
tradisional papua. & terhadap pedagang yang \\
& -Banyak pedagang yang & curang demi kebaikan dan \\
& curang soal harga & kenyamanan pengunjung \\
& makanan & \\
& & \\
& & \\
\end{tabular}

\section{KESIMPULAN}

Dari Hasil analisa faktor-faktor penentu pengembangan wisata Pantai Hamadi, didapat faktor-faktornya berupa:

1. Faktor Lingkungan Alamiah

2. Faktor Sarana Wisata

3. Faktor Desain Perancangan

4. Faktor Transportasi

5. Faktor Pelayanan

Setelah diperoleh faktor yang mempengaruhi tingkat pelayanan wisata Pantai Hamadi, Dirumuskan Arahan Peningkatan Pelayanannya berdasarkan fakta dan keadaan eksisting. Arahan pengembangan diperoleh dari hasil analisa deskriptif dan menghasilkan:

1. Lingkungan Alamiah, arahannya meliputi:

a. Pusat kegiatan sebaiknya difokuskan ke tengah kawasan wisata, karena daerah yang rawan abrasi di daerah tepi

b. Dilakukan pembibitan guna melestarikan keanekaragaman vegetasi dan tindakan pencegahan bencana abrasi dan pasang surut

c. Diperlukan dstribusi air bersih kedalam kamar bilas atau WC umum sehingga wisatawan dapat berbilas

2. Sarana Wisata, Arahannya meliputi:

a. Mengusulkan atraksi budaya seperti upacara adat port numbay, tarian yosim pancar kedalam salah satu agenda rutin Kawasan Wisata Pantai Hamadi

b. Sosialisasi kios-kios perdagangan kepada para pemilik kios dengan menurunkan tarif sewa

c. Pemanfaatan ruang-ruang kosong sebagai tempat istirahat wisatawan

3. Desain Perancangan, Arahannya meliputi:

a. Mengikutsertakan masyarakat dalam pengembangan wisata Pantai Hamadi Kota Jayapura, sehingga menumbuhkan rasa saling menjaga dan merawat dimasyarakat

b. Membangun kerjasama dengan Aparat TNI/POLRI dalam peningkatan mutu kualitas keamanan

4. Transportasi, arahannya meliputi:

a. Sosialisasi kepada masyarakat dan wisatawan dalam berkendara agar berkendara dengan baik dan berhati - hati

b. Perbaikan kualitas akses menuju kawasan wisata Pantai Hamadi Kota Jayapura

c. Sosialisasi tentang penggunaan transportasi umum

5. Pelayanan, arahannya meliputi:

a. Perlu dipertahankannya budaya tradisional dibidang kuliner seperti Papeda dan Ikan Tuna Asar

b. Pemberian Sanksi yang tegas terhadap pedagang yang curang demi kebaikan dan kenyamanan pengunjung 


\section{UCAPAN TERIMAKASIH}

Penulis E,W. mengucapkan terimakasih kepada Walikota Kota Jayapura, Kepala DKP kota Jayapura, Dinas Pendidikan Kota Jayapura, Bappeda Provinsi Papua dan Sekda Provinsi Papua yang telah membantu peneliti dalam mendapatkan informasi yang dibutuhkan serta kepada masyarakat di Kecamatan Sukapura yang telah bersedia menjadi responden dalam penelitian ini.

\section{DAFTAR PUSTAKA}

[1] Ariyanto, Ekonomi Pariwisata. Jakarta: Rineka Cipta, 2005.

[2] Bappeda, Rencana Induk Perencanaan Pariwisata Daerah Kota Jayapura. Jayapura.

[3] O. A. Yoeti, Perencanaan dan Pengembangan Pariwisata. Jakarta: PT Pradaya Paramita, 2008. 